\title{
Pesan Perdamaian dalam Video Klip Atouna EI Toufoule: Analisis Semiotik Charles Sanders Peirce
}

\author{
Arin Faridatul Azma* \\ Universitas Islam Negeri (UIN) Sunan Kalijaga, Yogyakarta, Indonesia
}

Peace Messages in the Atouna EI Toufoule Video Clip: Semiotic Analysis of Charles Sanders Peirce

E-Mail Address

faridaarin24@gmail.com

${ }^{*}$ Corresponding Author

Keywords

Semiotics;

peace messages;

atouna el toufoule

\begin{abstract}
The purpose of this article is to find out the description of peace messages in the Atouna El Toufoule video clip. In the video clip of Atouna El Toufoule, several signs have meaning. The study of meaning in this article uses a qualitative research methodology by analyzing images as data which is analyzed using Charles Sanders Peirce's semiotics in finding meaning through signs, objects, and interpretants. The results of this study indicate that sign is mostly motivated by social context and does not require excessive interpretation of meaning. The object takes the side of social life that occurs in Palestinian society. Interpretants also sometimes directly criticize social life, culture, and the environment around them. The video clip of Atouna El Toufoule contains a moral message and an invitation to create peace for children living in conflict areas. They need a vacation so they can feel peace and freedom in their lives.
\end{abstract}

\section{Pendahuluan}

Media komunikasi massa merupakan media yang bisa digunakan untuk menyampaikan sebuah pesan secara efisien. Media komunikasi massa turut berperan dalam membentuk pola pikir dan hubungan sosial suatu masyarakat. Selain itu, melalui berita ataupun hiburan juga dapat memberikan ilustrasi dan nilai-nilai yang ada pada masyarakat (Liliweri, 2003). Menurut Littlejohn (2005), di dalam komunikasi massa terjadi proses penyampaian pesan kepada masyarakat oleh organisasi media massa.

Banyak media yang bisa digunakan untuk menyampaikan pesan kepada masyarakat. Misalnya, melalui tayangan televisi, radio, majalah, surat kabar, buku, internet, dan bahkan bisa melalui media video klip pada musik. Di antara banyaknya media, suatu pesan bisa tersampaikan salah satunya adalah melalui video. Video saat ini mewakili dan akan mewakili di masa depan. Konten yang luas dan beragam mulai dari konten yang diproduksi secara professional, distribusi dan formatnya juga bervariasi mulai dari linier dan video in-stream non-linier ke video dalam tampilan dan kombinasikombinasinya dikemas secara menarik (Toppano, 2017). Video klip merupakan salah satu bentuk komunikasi yang dapat menyampaikan pesan dengan menggunakan audio visual. Selain itu, sebuah 
pesan yang akan disampaikan juga dapat diterima dengan baik melalui video klip. Video klip merupakan salah satu media komunikasi yang berkembang seiring dengan kemajuan teknologi. Berkembang pesatnya teknologi menyebabkan penduduk dunia dapat melihat kejadian di luar daerahnya dengan jelas tanpa perlu mendatangi daerah tersebut (Abbas, 2003).

Sebuah video dapat menyampaikan suatu pesan dengan baik kepada komunikan melalui gambar dan suara. Video mempunyai peran sebagai sarana baru untuk menyebarkan hiburan yang sudah menjadi kebiasaan, serta menyajikan cerita, peristiwa, musik, drama, lawak, dan yang lainnya kepada masyarakat (McQuail, 1987). Moller (2011) berpendapat bahwa video klip merupakan sebuah film pendek atau video yang mendampingi alunan musik yang pada umumnya seperti lagu. Video klip berfungsi sebagai alat pemasaran yang digunakan untuk mempromosikan album rekaman. Sama halnya dengan bahasa, video klip juga berkembang sebagai media komunikasi yang menunjukkan realitas sosial yang ada dalam suatu masyarakat.

Sebagai alat komunikasi massa, sebuah video mempunyai peran dalam hal menyampaikan suatu pesan kepada masyarakat. Manusia biasanya cenderung menyukai keindahan dan kesenangan. Melalui video klip sebuah lagu di mana lantunan musik diiringi dengan visualisasi gambar yang menarik, biasanya akan lebih cepat diingat oleh penikmat musik. Menurut Sari (2016), video klip merupakan salah satu bentuk dari komunikasi yang digunakan untuk menyampaikan pesan melalui audio visual. Selain itu, video klip digunakan dengan tujuan supaya pesan yang ingin disampaikan oleh pengarang atau pembuat video tersebut dapat sampai kepada komunikan dengan baik. Video klip juga dapat diartikan sebagai sebuah film lagu yang merupakan kombinasi seorang musisi ataupun grup dengan menyertakan gambar visual (Yulyaswir, 2019).

Melihat bahwa video klip merupakan sebuah sarana komunikasi untuk menyampaikan suatu pesan, maka pesan yang terkandung di dalam video klip perlu untuk dimaknai dan ditelusuri pesan apa yang terkandung di dalamnya. Hal ini bertujuan agar maksud dari gambar tersebut dapat tersampaikan secara baik kepada masyarakat atau siapapun yang menontonnya. Oleh karena itu, peneliti tertarik untuk meneliti pesan perdamaian dalam video klip yang berjudul Atouna El Toufoule (A'tūnà al-Ṭfülah). Dalam video klip ini mengisahkan sebuah kisah nyata yang terkait Palestina yang sedang mengalami kesedihan akibat serangan dari pihak Israel.

Dalam penelitian ini, peneliti akan membahas pesan perdamaian yang ada di dalam video klip Atouna El Toufoule menggunakan pendekatan semiotika. Kajian semiotika dapat mengungkapkan makna-makna yang terdapat dalam sebuah tanda. Peneliti ingin memaknai video tersebut dengan kajian semiotik Charles Sanders Peirce. Menurut Peirce, penanda adalah sesuatu yang dapat mewakili sesuatu yang lain atas dasar tertentu (Faruk, 2014). Semiotik merupakan tindakan, pengaruh, atau kerja sama antara tiga subjek; tanda, objek, dan interpretan, atau antara penanda, petanda, serta acuannya (Kamil, 2009). Oleh karena itu, semiotik dipandang sebagai ilmu tentang tanda atau sebagai ilmu yang mempelajari sistem-sistem, aturan-aturan, dan konvensi-konvensi yang memungkinkan tanda-tanda tersebut mempunyai arti. Ada dua prinsip "penanda” yakni yang menandai dan "petanda" yakni yang ditandai (Sangidu, 2007).

Terkait topik mengenai video klip Atouna El Toufoule, diperlukan adanya pembahasan mengenai tanda-tanda dalam video klip tersebut. Video klip tersebut menceritakan tentang kisah anak-anak di Palestina yang menjadi korban konflik dan perang di Gaza. Para penonton ketika menonton video klip tersebut dapat menghayati apa makna dan pesan yang terkandung di dalamnya. Terdapat beberapa kajian yang menjadikan video klip Atouna El Toufoule sebagai objeknya, di 
antaranya Muawanah (2019), "Pesan Perdamaian Nissa Sabyan dalam Lagu Atouna Et-Toufoule di Media Sosial Youtube: Analisis Framing”. Hasil penelitian ini membuktikan bahwa makna himbauan genjatan senjata (liburan) yang dapat dilakukan melalui lagu-lagu pada daerah konflik adalah agar supaya anak-anak dapat merasakan kedamaian dalam hatinya. Kemudian, Insani (2021), “The Social Facts of 1982's Lebanese War in A'tuna Tufuli Song by Remi Bandali: Riffaterre's Semiotic Analysis” yang mengungkapkan fakta-fakta sosial yang terjadi pada saat perang Lebanon tahun 1982. Di antara fakta-fakta sosial tersebut seperti kekacauan, kebakaran sepanjang hari, dan perebutan kebebasan dikarenakan tanah tersebut dianggap lemah dan tidak berdaya. Selain itu, kajian-kajian yang menggunakan semiotika model Charles Sanders Peirce juga telah banyak dilakukan. Di antaranya Ramadhan dkk (2018), Darajah (2020), dan Marwantika (2021). Berbeda dari kajian-kajian tersebut, penelitian ini fokus pada pemaknaan tanda-tanda semiotika triadic Peirce dan pesan perdamaian yang terkandung di dalam video klip Atouna El Toufoule. Hasil penelitian ini diharapkan mampu memberikan sumbangsih keilmuan, terutama dalam kajian semiotika khususnya model triadic Charles Sanders Peirce.

\section{Metode Penelitian}

Penelitian ini bersifat kajian pustaka (library research) dengan menjadikan video klip Atouna El Toufoule (A'tūnā al-Ṭüülah) di Youtube sebagai sumber data (Sholawatankuy, 2019). Pengumpulan data dilakukan dengan teknik dokumentasi, yaitu dengan cara mengelompokkan scene-scene, membaca, dan mencermati setiap gambar yang terdapat dalam video klip tersebut. Sementara itu, metode analisis data yang digunakan ini adalah metode kualitatif yang berupa deskriptif analisis. Metode ini dilakukan dengan cara mengemukakan data-data pada objek penelitian, kemudian dianalisis. Pada metode penelitian ini, untuk memperoleh sebuah data yang akan mendukung proses pengkajian dilakukan dengan cara mendeskripsikan secara umum gambar dari video klip Atouna El Toufoule. Lalu, dilanjutkan dengan analisis formal secara terperinci sesuai dengan kajian teori. Proses selanjutnya adalah interpretasi untuk mengungkapkan makna yang terkandung dalam video klip tersebut. Adapun proses interpretasi dilakukan dengan menggunakan teori semiotika Charles Sanders Peirce sebagai teori untuk membedah dalam pelaksanaan penelitian. Elemen-elemen Peirce berupa sign (tanda), interpretant (penerima tanda atau pemahaman makna), dan object (sasaran atau acuan).

\section{Hasil Penelitian dan Pembahasan}

A. Lirik Lagu Atouna El Toufoule

\section{أعطونا الطفولة}

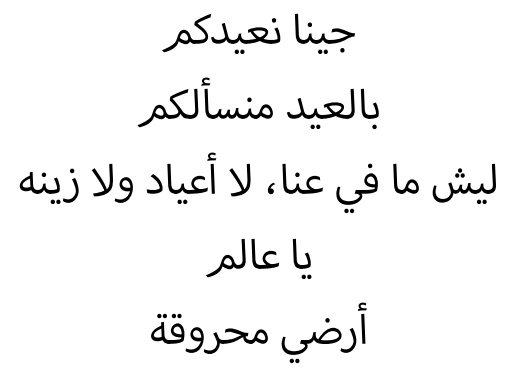




$$
\begin{aligned}
& \text { أرضي حريه مسروقة } \\
& \text { زمانه عم تحلم ، وبتسأل أيام } \\
& \text { وين الشمس الحلوة } \\
& \text { ورفوف الحمام } \\
& \text { يا عالم } \\
& \text { أرضي محروقة } \\
& \text { أرضي حريه مسروقة } \\
& \text { أرضي صغيرة، مثلي صغيرة }
\end{aligned}
$$

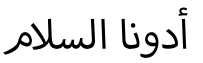

$$
\begin{aligned}
& \text { وأعطونا الطفولة } \\
& \text { أعطونا الطفولة } \\
& \text { أعطونا الطفولة } \\
& \text { أعطونا الطفولة } \\
& \text { أعطونا، أعطونا، أعطونا السلام } \\
& \text { أعطونا الطفولة } \\
& \text { أعطونا الطفولة } \\
& \text { أعطونا الطفولة } \\
& \text { أعطونا، أعطونا، أعطونا السلام }
\end{aligned}
$$

Kami datang dengan ucapan selamat berlibur

Dan selama liburan kami tanya kepadamu

Mengapa di tempat kami tidak ada dekorasi hari raya

$$
\text { Wahai dunia }
$$

Tanahku habis terbakar

Tanahku dicuri kebebasannya

Tanahku kecil, seperti aku, itu kecil

Berikan kedamaian

Berikan kami masa kecil

Berikan kami masa kecil

Berikan kami masa kecil

Berikan kami masa kecil

Berikan, berikan, berikan kami kedamaian

Berikan kami masa kecil

Berikan kami masa kecil

Berikan kami masa kecil

Berikan, berikan, berikan kami kedamaian 


\section{B. Triadic dalam Semiotika Charles Sanders Peirce}

Konsep semiotika dalam pandangan Peirce memunculkan tiga konsep utama, yaitu berdasarkan sistem triadic yang berupa representamen (sesuatu yang mewakili atau tanda yang mewakili sesuatu yang lain), object (sasaran atau acuan) dan interpretant (penerima tanda atau pemahaman makna). Representamen merupakan suatu unsur tanda yang mewakili sesuatu yang lainnya. Object merupakan sesuatu yang diwakili oleh representamen. Sementara itu, interpretant merupakan sebuah penafsiran atau makna sebuah tanda yang ada dalam fikiran si penerima (Zaimar \& Kusuma, 2014). Jadi, yang dimaksud dengan interpretant merupakan tanda yang ada di dalam fikiran penerima setelah ia melihat maupun mendengar representamen (penafsiran). Dalam penafsiran ini setiap orang dalam menafsirkan sesuatu pasti ada yang sama dan ada yang berbeda. Menurut Peirce, semua tanda itu memiliki objek dan penafsir (Nöth, 2011).

Konsep lain yang juga dikemukakan oleh Peirce adalah trikotomi tanda. Trikotomi tanda tersebut memuat firtsness, secondness dan thirdness. Ketiga trikotomi ini juga dibagi berdasarkan pembagiannya. Dalam mengkaji suatu objek, Peirce melihat melalui tiga jalur logika, yaitu hubungan representamen dengan representamen: qualisign, sinsign dan legisign. Dalam hubungan object dengan representamen berupa icon, indeks dan symbol (Suparno \& Kusumoriny, 2020). Sementara itu, dalam hubungan interpretant dan jenis representamen di antaranya, yaitu rbeme, dicent, qrgument (Rusmana, 2014). Peirce membedakan ikon dalam tiga macam, yaitu ikon topologis, diagramatik, dan metaforis (Nurgiyantoro, 2015).

Menurut Peirce, penalaran manusia senantiasa dilakukan melalui tanda. Maksudnya, manusia hanya dapat bernalar melalui tanda. Dalam pikirannya, logika sama dengan semiotika, dan semiotika dapat ditetapkan pada segala macam tanda (Suhariyadi, 2014), sehingga ada istilah teori segitiga makna (triangel meaning) atau hubungan triadic yang mana elemen utamanya ada sign, object, dan interpretant (Iskandar \& Lestari, 2016). Ketiganya merupakan subjek yang saling bekerja sama. Adapun yang dimaksud subjek adalah entitas semiotika yang sifatnya abstrak, yang tidak dipengaruhi oleh kebiasaan berkomunikasi secara konkret (Asriningsari \& Umaya, 2012).

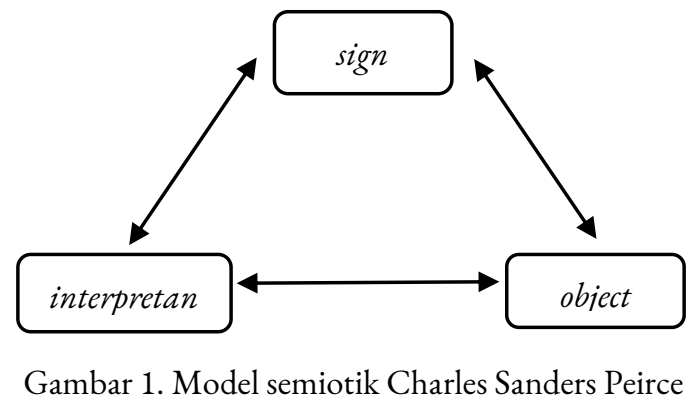

C. Video Klip Atouna El Toufoule: Gambaran tentang Pesan Perdamaian

Dalam pembahasan ini, peneliti akan menganalisis pesan perdamaian pada video klip Atouna El Toufoule dengan menggunakan analisis semiotika Charles Sanders Peirce. Peneliti akan menampilkan beberapa gambar yang merupakan bagian dari video klip Atouna El Toufoule. 

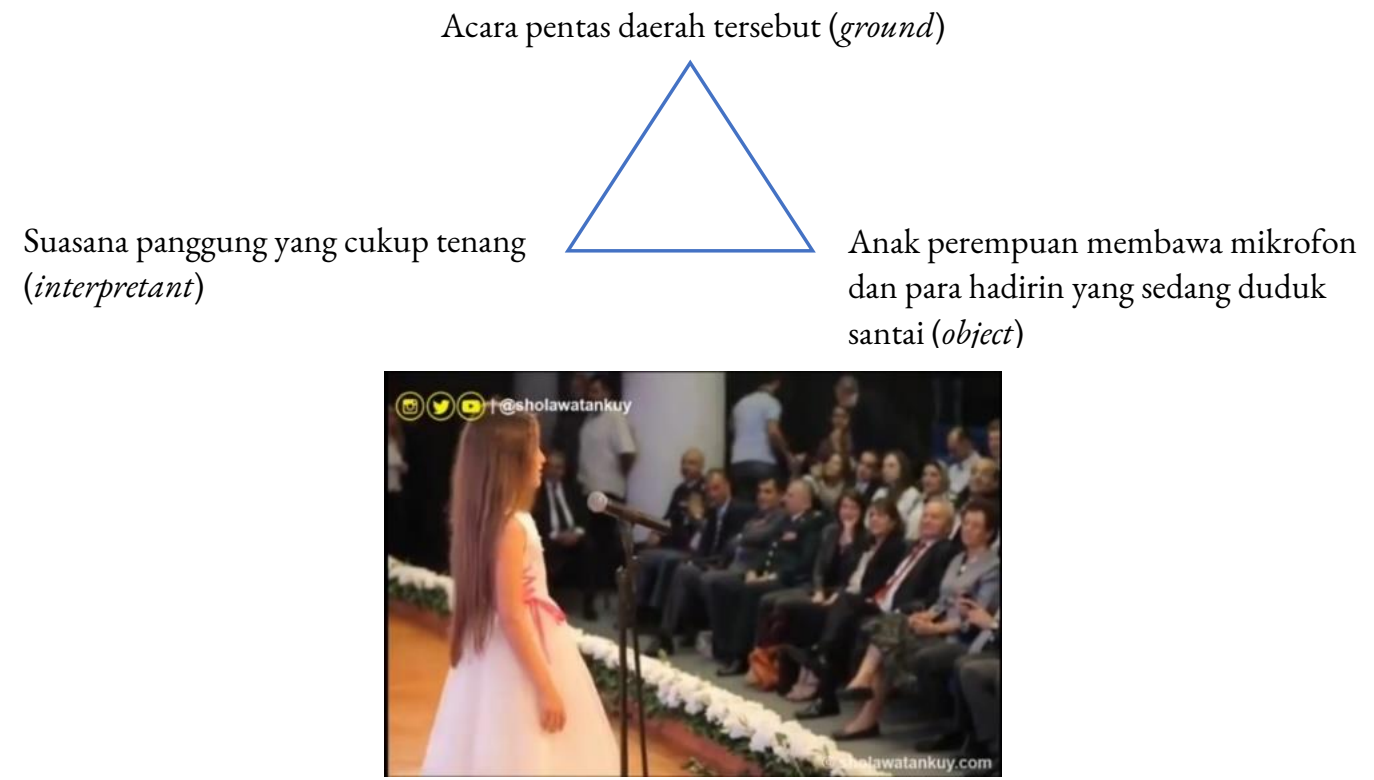

Gambar 1. Acara pentas

(Sholawatankuy, 2019)

Gambar 1 menunjukkan sebuah acara pentas di daerah tersebut yang suasananya cukup tenang dan dihadiri oleh para hadirin. Hal ini menunjukkan suatu tanda yang berhubungan langsung dengan objeknya. Adapun objek dari teori triadik semiotika Peirce pada gambar tersebut adalah terdapatnya anak perempuan membawa mikrofon dan para hadirin yang sedang duduk santai. Di sana tampak para hadirin sedang mendengarkan dengan seksama seorang anak perempuan yang sedang bernyanyi dan para hadirin menikmati acara tersebut. Sementara itu, dengan adanya panggung menunjukkan sebuah tanda yang berhubungan langsung dengan objeknya, yaitu anak perempuan membawa mikrofon dan para hadirin yang sedang duduk santai. Mereka tampak fokus dan tenang. Hal tersebut memunculkan pemahaman makna gambar dan objek tentang suasana panggung yang cukup tenang.

Berdasarkan analisis pada gambar tersebut, maka dapat ditafsirkan bahwa terdapat seorang anak perempuan yang sedang berdiri di depan mikrofon pada sebuah acara yang dihadiri oleh banyak orang. Pada gambar tersebut menunjukkan bahwa anak perempuan tersebut sedang bernyanyi. Dari pandangan ini kemudian menimbulkan pemaknaan bahwa anak perempuan itu sedang menghibur atau mengisi sebuah acara besar dengan bernyanyi di hadapan banyak orang. Mereka yang hadir pun menikmati suasananya dan terlihat dari para hadirin yang sedang fokus dan duduk dengan tenang memperhatikan anak perempuan tersebut.

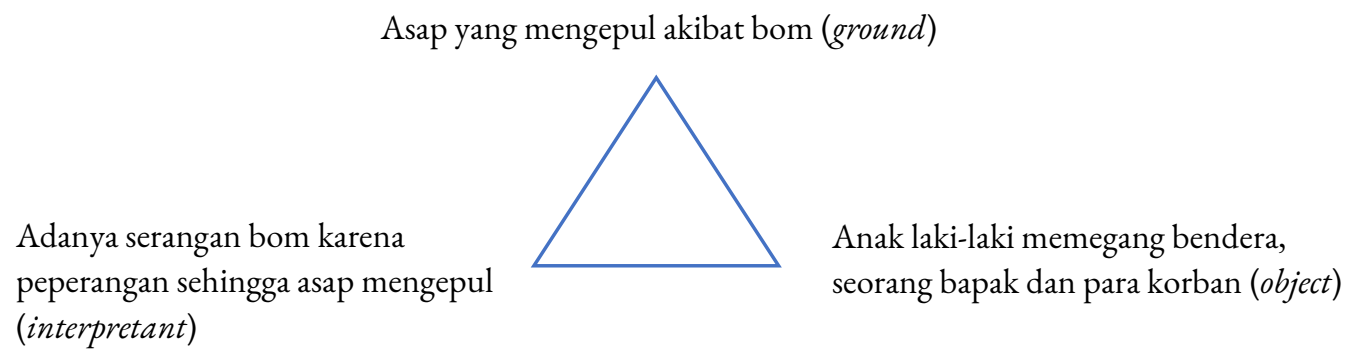




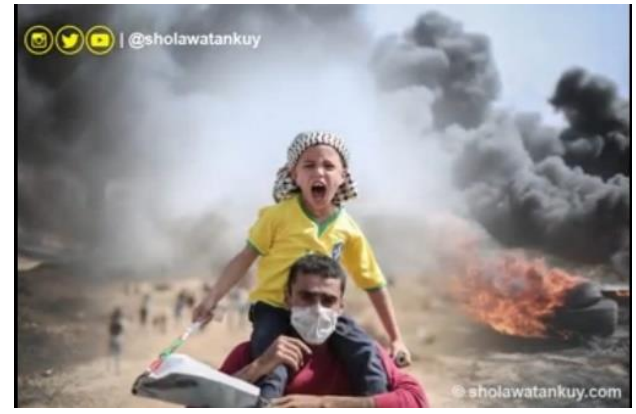

Gambar 2. Asap yang mengepul akibat bom

(Sholawatankuy, 2019)

Gambar 2 menunjukkan adanya tanda asap yang mengepul akibat serangan bom. Ini menunjukkan tanda bahwa sedang ada peperangan yang terjadi di Palestina yang dilakukan oleh negara Israel yang ingin menguasai tanah Palestina. Gambar tersebut juga menunjukkan keadaan sekitar yang sedang kacau. Kemudian, objek dari gambar tersebut adalah ada seorang anak laki-laki memegang bendera yang digendong oleh seorang bapak dan terlihat para korban. Di sana tampak para korban atau masyarakat Palestina yang sedang kebingungan dan berlarian untuk menyelamatkan diri. Semantara itu, adanya asap yang mengepul menunjukkan sebuah tanda yang berhubungan langsung dengan objeknya, yaitu anak laki-laki memegang bendera yang sedang digendong seorang bapak dan para korban yang berlarian. Ini memunculkan pemahaman makna bahwa di negara Palestina sedang terjadi peperangan di mana Israel meluncurkan serangan bom dan akhirnya menimbulkan api dan asap mengepul. Suasana di negara tersebut pun menjadi kacau.
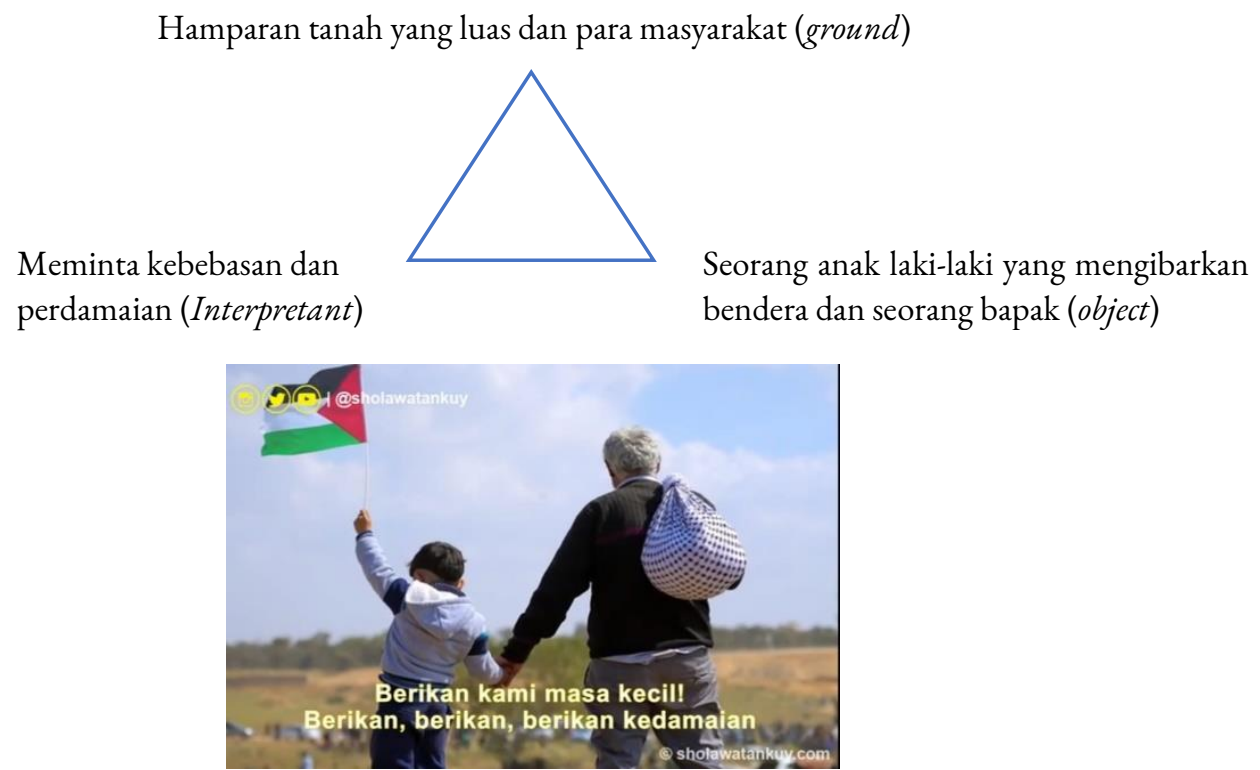

Gambar 3. Hamparan tanah yang luas dan para masyarakat

(Sholawatankuy, 2019)

Gambar 3 menunjukkan sebuah lokasi hamparan tanah yang luas di mana banyak para masyarakat yang berlalu lalang. Di sana menunjukkan suatu tanda yang berhubungan langsung dengan objeknya. Adapun objek pada gambar tersebut adalah ada seorang anak laki-laki yang sedang berdiri bersama bapaknya dan mengibarkan bendera. Sementara itu, dari hamparan tanah yang luas dan para masyarakat menjadi sebuah tanda yang berhubungan langsung dengan objek, yaitu seorang 
anak laki-laki dan seorang bapak yang sedang berdiri di suatu tempat yang tinggi. Lalu, anak tersebut sambil mengibarkan bendera. Ini memunculkan pemahaman bahwa makna dari gambar dan objek tersebut menggambarkan seorang anak yang ditemani seorang bapak. Anak tersebut mengibarkan sebuah bendera dengan menyatakan meminta kebebasan dan perdamaian atas apa yang telah terjadi atau menimpa pada masyarakat dan negaranya.

Berdasarkan analisis pada gambar tersebut dapat ditafsirkan bahwa terdapat dua orang, yaitu anak kecil dan seorang bapak yang berdiri dengan mengibarkan bendera negaranya sambal teriak "berikan, berikan, berikan kedamaian". Ini menimbulkan pemaknaan bahwa mereka mewakili masyarakat Palestina yang menginginkan sebuah kedamaian, ketenteraman dan kebahagiaan di negaranya. Adapun usaha yang mereka lakukan adalah dengan mengibarkan bendera negaranya sambil menyatakan "berikan kebebasan" sebagai bentuk untuk mendapatkan kebebasan, keadilan, dan kebahagiaan agar kembali dalam kehidupan mereka.
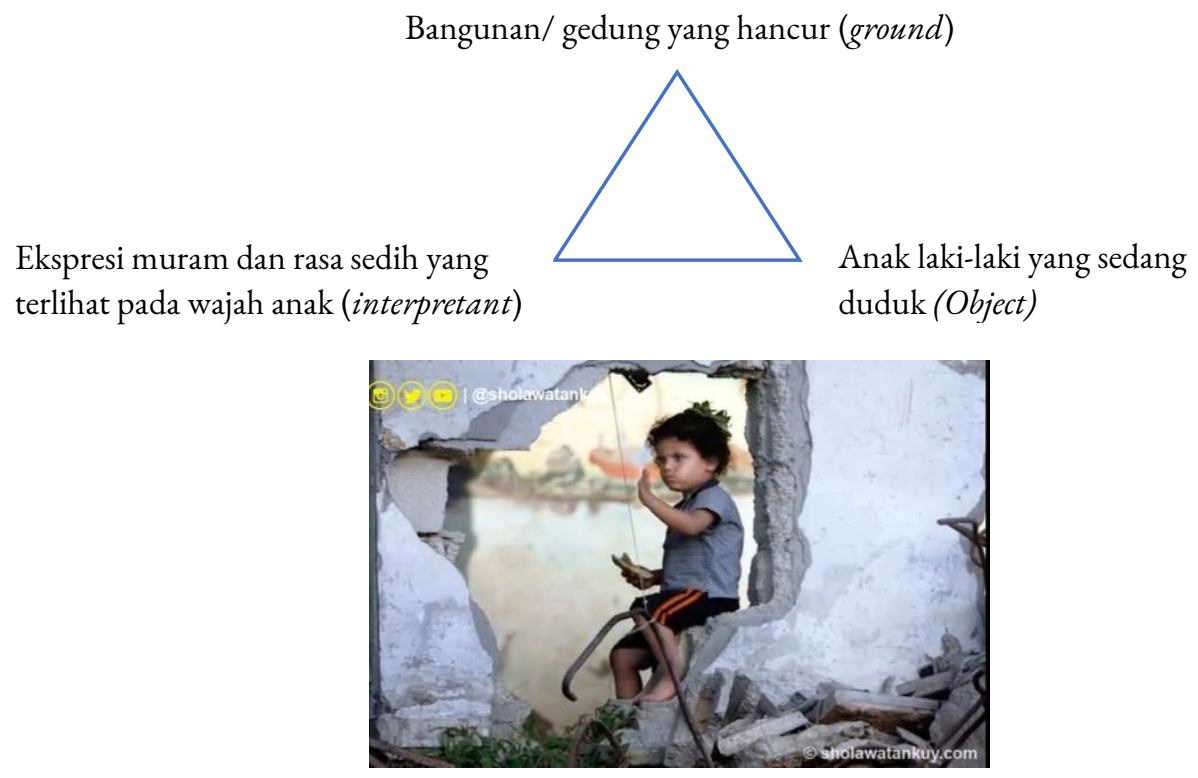

Gambar 4. Bangunan/ gedung yang hancur (Sholawatankuy, 2019)

Gambar 4 menunjukkan bangunan atau gedung yang hancur dengan suatu tanda dimana ada sesuatu yang terjadi pada lokasi tersebut. Adapun objeknya adalah potret anak laki-laki yang duduk sendirian berada tepat di sekitar lokasi bangunan atau gedung yang telah hancur. Keadaan ini menggambarkan suasana hati dan perasaan yang sedang dirasakan anak laki-laki tersebut. Sementara itu, bangunan atau gedung yang hancur dan roboh dinyatakan sebagai tanda yang berhubungan dengan objeknya, yaitu ekspresi muram dan rasa sedih yang terlihat pada wajah anak laki-laki. Ini memunculkan makna dari gambar dan objek tersebut bahwa anak ini berada pada tempat yang berantakan akibat peperangan sehingga raut wajah anak tersebut pun tampak sedang sedih meratapi suasana yang telah terjadi.

Dari gambar tersebut dapat ditafsirkan bahwa akibat adanya peperangan dan serangan bom yang diluncurkan oleh pihak Israel, menyebabkan hancurnya bangunan-bangunan beserta isinya di negara Palestina sehingga menimbulkan banyaknya korban. Pada gambar tersebut terlihat seorang anak laki-laki sedang duduk seorang diri. Ini menimbulkan pemaknaan bahwa anak laki-laki tersebut 
termasuk salah satu korban dari peperangan yang tinggal seorang diri karena kehilangan atau terpisah dari keluarga, saudara, teman-teman dan orang-orang yang ada di sekelilingnya. Di usianya saat ini seharusnya ia masih menikmati bermain bersama teman-temannya, namun ia justru harus merasa kesedihan dan kesepian akibat kekacauan yang terjadi di negaranya.
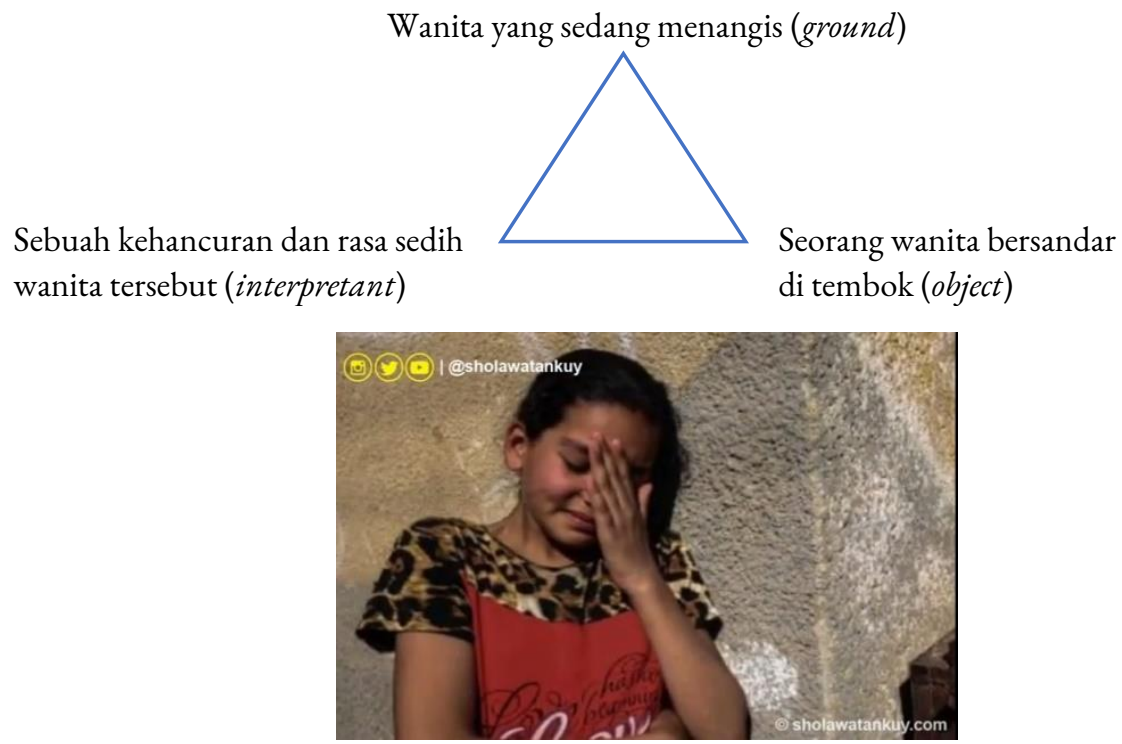

Gambar 5. Wanita yang sedang menangis

(Sholawatankuy, 2019)

Gambar 5 menunjukkan seorang wanita yang sedang menangis. Ini menunjukkan suatu tanda yang berhubungan langsung dengan objeknya. Adapun objek berdasarkan teori triadik semiotika Peirce pada gambar tersebut adalah seorang wanita yang sedang bersandar di tembok dan menangis. Keadaan ini menggambarkan suasana hati dan perasaan yang sedang dirasakan oleh si wanita tersebut. Sementara itu, wanita yang sedang menangis dinyatakan sebagai tanda yang berhubungan dengan objeknya, yaitu seorang wanita yang sedang bersandar di tembok. Ini kemudian memunculkan pemahaman makna dari gambar dan objek tersebut bahwa wanita tersebut tampak sendirian dan sedang sedih merasakan kehancuran di dalam hatinya dikarenakan kehilangan keluarga dan orang-orang yang dicintainya akibat dari peperangan yang terjadi.

Berdasarkan analisis pada gambar di atas, dapat ditafsirkan bahwa terdapat seorang wanita yang sedang duduk dan mengusap air matanya. Pada gambar tersebut, menimbulkan pemaknaan adanya kesedihan mendalam yang sedang dirasakan oleh wanita tersebut. Kesedihan yang disebabkan kehilangan anak dan orang-orang sekelilingnya yang ia sayangi. Wanita itu terlihat sedang meratapi hidupnya dan seakan meluapkan kesedihannya dengan menangis karena seakan merasa tidak kuat lagi menahan rasa kesedihan yang sedang ia alami.

Perdamaian atau yang dalam Islam dikenal dengan kata al-salām. Keduanya, al-salām dan Islam sama-sama mengajak seluruh umat manusia kepada ketenteraman, keamanan, ketenangan, dan kedamaian. Perdamaian dapat merujuk kepada persetujuan untuk mengakhiri dan meniadakan peperangan, atau sebuah periode di mana sebuah angkatan bersenjata tidak memerangi musuh (Hidayat, 2017). 
Terdapat konflik di antara kedua negara, yaitu Palestina dan Israel. Adapun penyebabnya adalah pemahaman atas agama yang berbeda yang dianut oleh keduanya, yaitu Islam dan Yahudi. Tanah di Palestina yang diperebutkan merupakan tanah suci, karena di atas tanah tersebut berdiri Masjid alAqșā yang menjadi kiblat pertama sebelum umat muslim menggunakan ka'bah sebagai kiblat mereka (Al-Ghadiry, 2010). Namun, tepat di bawah masjid terdapat ratapan tembok sebagai tempat untuk memberikan penghormatan bagi umat Yahudi (Bakar, 2008). Oleh sebab itu, tanah yang diperebutkan oleh umat Islam dan Yahudi mempunyai nilai historis dan keagamaan yang tinggi. Hal inilah yang menyebabkan Israel melakukan serangan bom terhadap Palestina.

Dalam video klip Atouna El Toufoule menayangkan sebuah ajakan kepada semua penonton atau pendengarnya untuk menciptakan perdamaian bagi anak-anak yang hidup pada area konflik. Mereka juga menginginkan kebebasan, ketenteraman, dan perdamaian dalam kehidupannya agar dapat menikmati masa kecilnya dengan bermain-main dengan teman sebayanya. Selain itu, pada video klip tersebut menceritakan dan menggambarkan anak-anak yang meminta masa kecilnya untuk dikembalikan, meminta adanya kebebasan dan perdamaian. Meski demikian, mereka menyadari bahwa tanahnya telah hilang dan negaranya telah hancur akibat serangan bom yang diluncurkan oleh pihak Israel. Selain mereka tidak bisa menikmati masa kecilnya, mereka pun juga harus merasakan kehilangan dan berpisah dari keluarga, saudara, teman-teman, bahkan orang-orang yang ada di sekelilingnya. Pada video klip tersebut mengandung pesan moral bahwa anak-anak yang hidup di daerah konflik ingin mendapatkan kedamaian, ketenteraman, dan kebahagiaan dalam hidupnya, layaknya anak-anak yang hidup di negara lainnya.

\section{Simpulan}

Berdasarkan hasil pembahasan yang telah diuraikan, dapat diambil kesimpulan bahwa (1) sign yang ada pada gambar pertama sampai dengan gambar kelima pada video klip Atouna El Toufoule banyak dilatarbelakangi oleh konteks sosial dan tidak membutuhkan interpretasi makna yang berlebihan; (2) object yang ada pada gambar-gambar di video klip tersebut mengambil sisi kehidupan sosial, khususnya yang terjadi pada masyarakat Palestina; (3) interpretant yang terdapat pada gambargambar di video klip tersebut juga terkadang secara langsung mengkritik kehidupan sosial, budaya, dan lingkungan yang ada di sekitarnya; (4) video klip Atouna El Toufoule mengandung pesan moral dan ajakan untuk menciptakan perdamaian bagi anak-anak yang tinggal di daerah konflik. Mereka memerlukan kedamaian dan kebebasan dalam hidupnya.

\section{Daftar Rujukan}

Abbas, B. (2003). Komunikasi internasional: peranan dan permasalabannya. Jakarta: IISIP.

Al-Ghadiry, F. (2010). Sejarah Palestina asal-muasal konflik Palestina-Israel (Ibob, Penerjemah). Yogyakarta: Book Marks.

Asriningsari, A., \& Umaya, N. M. (2012). Semiotika teori dan aplikasi pada karya sastra. Semarang: IKIP PGRI Semarang Press.

Bakar, A. (2008). Berebut tanah suci Palestina. Yogyakarta: Pustaka Insan Madani.

Darajah, U. (2020). Iklan Satāir panasonic al-hawā̄ìah dalam koran al-ahrām, Mesir: Analisis Semiotik Peirce. Al-Ma'rifab: Jurnal Budaya, Bahasa, dan Sastra Arab, 17(2), 171-178. doi:10.21009/almakrifah.17.02.07 
Faruk. (2014). Metode penelitian sastra: Sebuah penjelajahan awal. Yogyakarta: Pustaka Pelajar. Hidayat, N. (2017). Nilai-nilai ajaran islam tentang perdamaian: Kajian antara teori dan praktek. Jurnal Aplikasi Ilmu-Ilmu Agama, 17(1), 15-24. doi:10.14421/aplikasia.v17i1.1271

Insani, H. P. D. (2021). The social facts of 1982's lebanese war in a'tuna tufuli song by Remi Bandali: Riffaterre's Semiotic Analysis. Jurnal CMES, 14(1), 69-79. doi:10.20961/cmes.15.1.50740

Iskandar, D. S., \& Lestari, R. (2016). Mitos dalam jurnalisme. Yogyakarta: Andi.

Kamil, S. (2009). Teori kritik sastra Arab klasik dan modern. Jakarta: Rajagrafindo Persada.

Liliweri, A. (2003). Komunikasi antar pribadi. Jakarta: Pandu.

Littlejohn, S. W. (2002). Theories of human communication ( $7^{\text {th }}$ ed.). California: Wadsworth Group. Marwantika, A. I. (2021). The sacralization of the myth of prohibition of leaving the house at dusk in sandekala film: Charles sanders peirce's semiotic analysis. Mubarrik: Jurnal Dakwah dan Sosial, 4(01), 33-46. doi:10.37680/muharrik.v3i02.553

McQuail, D. (1987). Teori komunikasi massa. Jakarta: Erlangga.

Moller, D. (2011). Redifining music video. California: Major Written Assessment.

Muawanah, S. (2019). Pesan perdamaian Nissa Sabyan dalam lagu atouna et-toufoule di media sosial youtube: Analisis framing. (Skripsi). Universitas Islam Negeri Sunan Ampel, Surabaya, Jawa Timur.

Nöth, W. (2011). Representation and reference according to peirce. International Journal of Signs and Semiotics Systems, 1(2), 28-39. doi: 10.4018/ijsss.2011070102

Nurgiyantoro, B. (2015). Teori pengkajian fiksi. Yogyakarta: Gadjah Mada University Press.

Ramadhan, F. M., Delardhi, S. N., \& El Fauziah, U. N. (2018). Sign analysis of the instagram user using semiotic Charles S. Peirce. Project: Professional Journal of English Education, 1(5), 631644. doi:10.22460/project.v1i5

Rusmana, D. (2014). Filsafat semiotika. Bandung: CV. Pustaka Setia.

Sangidu. (2007). Penelitian sastra: Pendekatan, teori, metode, teknik, dan kiat. Yogyakarta: Unit Penerbitan Sastra Asia Barat.

Sari, N. W. (2016). Analisis semiotik pesan perdamaian pada video klip salam alaikum Harris J (Skripsi). UIN Syarif Hidayatullah, Jakarta.

Sholawatankuy. (2021, June 20). Atouna el toufoule (terjemahan) [Video]. https://www.youtube.com/watch?v=GehCaJPPO4c\&feature=youtu.be

Suhariyadi. (2014). Pengantar ilmu sastra orientasi penelitian sastra. Lamongan: Pustaka Ilalang.

Suparno, D., \& Kusumoriny, L. A. (2020). The semiotics analysis on the environment in the “journey to atlantis” picture book. Lexeme: Journal of Linguistics and Applied Linguistics, 2(1), 1-10. doi:10.32493/ljlal.v2i1.6986

Toppano, E. (2017). Semiotik annotation of video commercials: why the artifact is the way it is? WEB 2017: The Fifth International Conference on Building and Exploring Web Based Environments, 1(3), 45-51. Retrieved from https://core.ac.uk.

Yulyaswir, P. (2019). Representasi budaya jawa dalam video klip tersimpan di hati: Analisis Semiotika Charles Sanders Peirce (Skripsi). UIN Sultan Syarif Kasim, Riau.

Zaimar, S., \& Kusuma, Okke. (2014). Semiotika dalam analisis karya sastra. Depok: PT. Komodo Books. 
Al-Ma'rifah: Jurnal Budaya, Bahasa, dan Sastra Arab, Vol. 18, No. 2, October 2021, 139-150

This page intentionally left blank

150 | http://journal.unj.ac.id/unj/index.php/jba/index 